\title{
Measurements of Material Properties Using Differential Capacitive Strain Sensors
}

\author{
Larry L. Chu, Long Que, Member, IEEE, and Yogesh B. Gianchandani, Member, IEEE
}

\begin{abstract}
This paper describes a laterally deflecting micromachined device that offers high sensitivity and wide dynamic range to electronically monitor the thermal expansion coefficient, tensile and compressive residual strain and Young's modulus of microstructural materials, as well as the temperature dependence of these properties. The device uses sidewall capacitance between interdigitated tines to sense displacement caused by the release of residual stress in bent-beam suspension. Electrostatic force is used to obtain load-deflection profiles. The suspensions and tines are arranged such that output is a differential readout, immune to common mode parasitic capacitance. Analytical and numerical modeling results are presented and the device concept is verified by three different fabrication approaches using polysilicon and nickel as structural materials. Measured values of residual strain, thermal expansion and Young's modulus are very consistent with measurements taken by other approaches and those reported previously. For example, the residual strain in certain electrodeposited Ni structures was tracked from 68.5 microstrain at $23^{\circ} \mathrm{C}$ to -420 microstrain at $130^{\circ} \mathrm{C}$, providing an expansion coefficient of $8.2 \mathrm{ppm} / \mathrm{K}$; the best fit Young's modulus provided by the device was 115 GPa.

[737]
\end{abstract}

Index Terms-Capacitive measurement, strain, temperature coefficient, Young's modulus.

\section{INTRODUCTION}

$\mathbf{M}$ ONITORING the mechanical properties of structural materials is a critical challenge in MEMS research and manufacturing. Device performance parameters are sensitive to variations in Young's modulus $(E)$, residual strain $(e)$, residual stress $(\sigma)$ and the thermal expansion coefficient $(\alpha)$ of structural materials, which can vary with manufacturing conditions. It is particularly challenging to control these properties in additive fabrication processes, in which the structural material is deposited onto a substrate wafer. For example, residual stress in a thin film of polysilicon formed by low pressure chemical vapor deposition (LPCVD) may vary with deposition temperature, pressure, doping, as well as post-deposition anneal conditions [1], [2]. Packaging variables such as the choice of packaging

Manuscript received August 3, 2001; revised March 24, 2002. This work was performed at the University of Wisconsin, Madison, and supported in part by an Industrial and Economic Development Research program award from the State of Wisconsin and by Canopus Systems, Inc., through U.S. Army Aviation and Missile Command (AMCOM) contract DAAH01-00-C-R104. Subject Editor R. T. Howe.

L. L. Chu is with the Department of Electrical and Computer Engineering, University of Wisconsin, Madison, 53706 WI USA.

L. Que is with OpticNet, Inc., Hayward, CA 94545 USA.

Y. B. Gianchandani was with the University of Wisconsin, Madison, 53706 WI USA. He is now with the Electrical Computer Science Department, University of Michigan, Ann Arbor, MI 48109-2122 USA (e-mail yogesh@umich.edu).

Digital Object Identifier 10.1109/JMEMS.2002.803277. and die attachment materials and deployment conditions such as operating temperature and humidity can also have an impact. The ability to directly monitor select properties would allow accurate compensation of device response to changing conditions. The properties of primary interest in this study are strain and Young's modulus, which are related by stress. In addition, the coefficient of thermal expansion is studied for cases in which thermal stresses are significant.

Average stress in a thin film can be monitored by commercial tools from the change in curvature that it induces on substrate wafer [3]. A number of micromachined strain sensors complement this method, offering spatial resolution of a few hundred microns. Although some of these require mechanical actuation [4], [5], most involve passive structures that are designed to deform measurably under the residual stress when they are released from the substrate [6]-[12]. These deformations are measured visually, sometimes using a micromachined vernier. Although useful in a laboratory setting, this method is not necessarily convenient for high volume manufacturing. In this context, an electrical readout better conforms to standard integrated circuit (IC) test equipment and procedures. More importantly, an optical or visual readout renders the strain sensor useless upon packaging, eliminating many conceivable applications, whereas an electronic readout potentially permits the strain sensor to be co-fabricated or co-packaged with another device such as an accelerometer or gyroscope, improving the system accuracy by offering real-time or test-mode calibration over the lifetime of its deployment.

An electrostatic pull-in technique has been used in the past to electronically monitor residual stress [13], [14]. In this method, a clamped bridge or diaphragm is deflected by applying a voltage bias to an electrode located under it, generally to the point that it collapses, although this is not always necessary because the capacitance between the actuation electrode and the microstructure can be used to gauge displacement and obtain a load line [15], [16]. This technique is better suited for tensile materials because moderate compressive forces may buckle the structure and render it unusable. In addition, the vertical deflection of the bridge or diaphragm (perpendicular to the substrate) may be less appealing for devices that are designed to deflect laterally if the structural material is anisotropic (e.g., single crystal silicon or polysilicon with a preferential grain orientation). When the pull-in technique is used, stiction forces may prevent recovery from collapse, limiting the lifetime of a device or the repeatability of a measurement. Furthermore, the fabrication process must permit the inclusion of an electrode under the microstructure. 
This paper describes a micromachined strain sensor that provides an electronic readout from a laterally deflecting structure 1 that combines the behavior of passively deformed and electrostatically actuated structures to provide certain unique capabilities. The readout is a differential capacitance, which is immune to common mode parasitics. Moreover, a single device is not only suitable for monitoring a wide range of tensile and compressive strains, but also yields the Young's modulus of the structural material upon the execution of a simple capacitance versus voltage $(C-V)$ test such as that used routinely in characterization of MOS transistors. It is a single-layer device and thus simple to fabricate. Since the structure is never deflected to the point of collapse, it is expected to provide a long deployment lifetime and is potentially suitable for the postpackaging monitoring of material properties in real-time or test-mode operation.

In this effort, the operation of the differential capacitive strain sensor is theoretically evaluated and experimentally verified. Section II describes the operation and modeling of the capacitive strain sensor. The discussion also includes the effects of nonidealities to the performance of the sensor. Section III outlines the three distinct fabrication sequences used to validate the device. Section IV presents the measured results for three sets of fabricated devices. It is demonstrated that these devices can be used not only to measure the stated properties of both tensile and compressive materials but also to provide the temperature coefficient of these properties. Finally, Section V summarizes the findings in this effort.

\section{Modeling}

This section presents analytical and numerical models related to both the strain measurement and the Young's modulus measurement. The impact of structural nonidealities is also evaluated.

\section{A. Basic Operation}

In the differential capacitive strain sensor [see Fig. 1(a)], a series of ribs are suspended above the substrate by bent-beams. Bent-beam suspensions relieve both tensile and compressive residual stresses by inward and outward motions of the apex, respectively. The ribs support interdigitated tines that function as electrodes for the sidewall capacitors. The suspensions and tines are arranged such that the capacitance on one side of a rib increases as the other decreases. In other words, in response to residual strain in the structural material, the structures labeled A move in the opposite direction to those labeled B and C. This permits a differential readout that is immune to common mode parasitics. The residual strain in the structural material is determined from the differential capacitance, defined as $\Delta C=$ $C_{A B}-C_{A C}$, which is $>0$ in tension and $<0$ in compression. The Young's modulus of the material is determined from the curvature of the plot of $C_{A B}$ (or conversely, $C_{A C}$ ) versus an applied bias voltage between elements A and B (or C). The bias voltage causes an electrostatic force, resulting in a displacement that is measured by the change in capacitance. The displacement

${ }^{1}$ Portions of this article have occurred in conference abstract form in [17], [18], and [19].

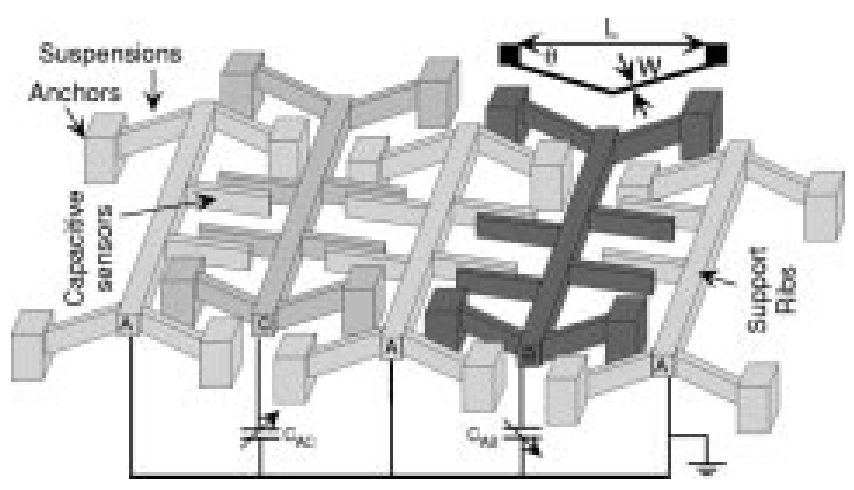

(a)
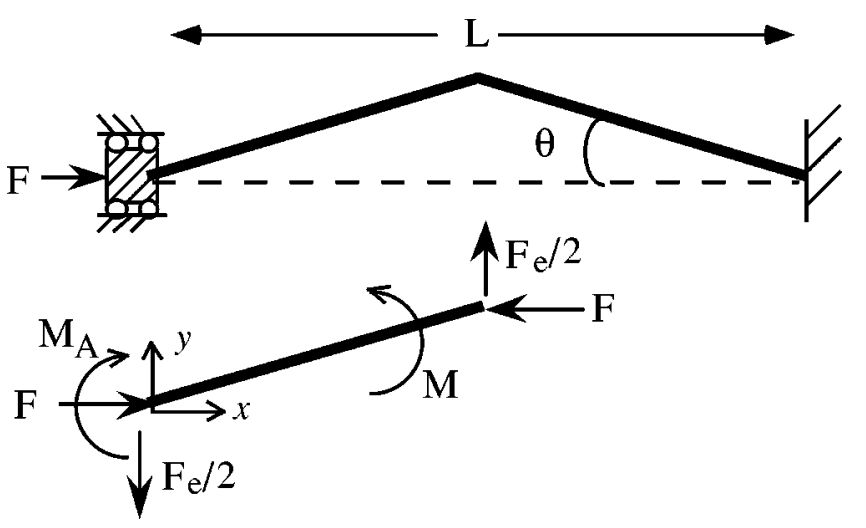

(b)

Fig. 1. (a) Schematic of the differential capacitive strain sensor and (b) definition of bent-beam dimensions.

is related to the stiffness of the suspension, which is proportional to the Young's modulus. The curves obtained are referred to as $C-V$ curves. The procedure for determining Young's modulus is, therefore, similar to the $C-V$ test commonly used for MOS transistors.

Bent-beams are excellent transducers for converting both tensile and compressive residual strain to displacement [10]. The sensitivity and range of the deformation in the bent beam suspension are a function of its bending angle and can be customized to address the needs of a particular application or fabrication process. In general, the devices have high sensitivity and a wide dynamic range. A number of devices have been designed by varying the structural design parameters, with target sensitivities in the range of $0.1-1 \mathrm{fF} / \mathrm{MPa}$ and a range of about $\pm 300 \mathrm{MPa}$.

The displacement of the bent-beams in response to residual stresses can be calculated analytically. Using variables defined in Fig. 1(b), the governing equation is

$$
E I \cdot \frac{\partial^{2} y}{\partial x^{2}}=M=M_{A}-F \cdot y
$$

with the boundary conditions

$$
\left.y\right|_{x=0}=0 ;\left.\quad \frac{\partial y}{\partial x}\right|_{x=0}=\left.\frac{\partial y}{\partial x}\right|_{x=L / 2}=\tan \theta
$$

where $E I$ is the flexural rigidity of the suspension, $F$ is the axial force used to model the effects of stress and $L$ is the suspension 


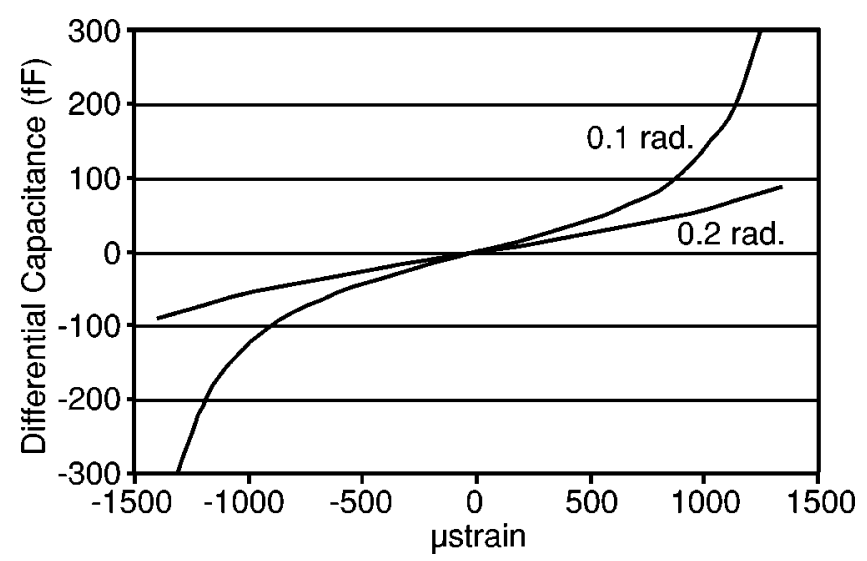

Fig. 2. Sensor response to residual strain for $200-\mu \mathrm{m}$ long, $5-\mu \mathrm{m}$ wide, suspensions which are $4-\mu \mathrm{m}$ in thickness; assuming 10 tines per side with an overlap distance of $167 \mu \mathrm{m}$ and a nominal gap of $1 \mu \mathrm{m}$.

length. In the absence of any externally applied forces the displacement of the apex is given by (3) for tensile material and (4) for compressive materials

$$
\begin{aligned}
d_{\text {apex-tensile }} & =\tan \theta \cdot\left[\frac{2}{k} \cdot \tanh \frac{k \cdot L}{4}-\frac{L}{2}\right] \\
d_{\text {apex-compressive }} & =\tan \theta \cdot\left[\frac{2}{k} \cdot \tan \frac{k \cdot L}{4}-\frac{L}{2}\right]
\end{aligned}
$$

where $k=\sqrt{F /(E I)}$. The response of the sensor is plotted as a function of residual strain in Fig. 2. The analytical model closely matches finite element analysis results in this range of dimensions [10].

\section{B. Capacitance-Voltage $(\mathrm{C}-\mathrm{V})$}

Whereas strain is measured from the passive deformation of the bent beams in response to the residual stress, the measurement of Young's modulus requires an applied electrostatic force. This is provided by a voltage bias between two adjacent ribs. The applied voltage changes the separation between the tines, which is monitored capacitively. The slope of the $C-V$ curve can then be related to the Young's Modulus since the device dimensions are known.

The $C-V$ modeling approach was conceptually similar to those described in [14], [15] and [16]. Capacitance between tines was numerically modeled using FastCap ${ }^{\mathrm{TM}}$ [20]. It was determined for a range of separations between tines and stored in a look-up table. Starting with the zero-bias separation between the tines, separation was decremented in small intervals. At each separation, the capacitance was determined from the look-up table, while the corresponding bias voltage required to cause the displacement was determined from force balance by equating the electrostatic attractive force to the mechanical restoring force:

$$
k_{\mathrm{eff}} \cdot y=\frac{V_{\mathrm{Bias}}^{2}}{2} \cdot \frac{\partial C_{A B}}{\partial y}
$$

where $k_{\text {eff }}$ is the effective mechanical spring constant of each structural unit including two bent-beam suspensions, one rib and associated tines; $y$ is the in-plane displacement from the zero-bias position. The spring constant has three components

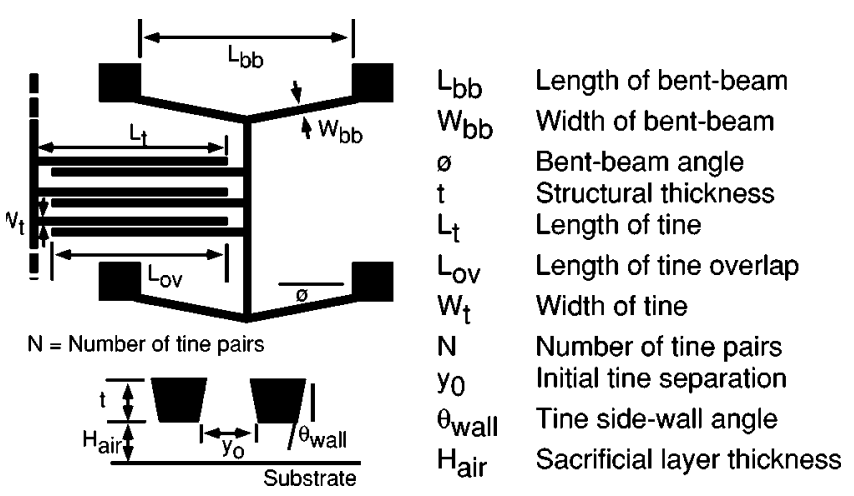

Fig. 3. Definitions of dimensional parameters needed for modeling of nonidealities.

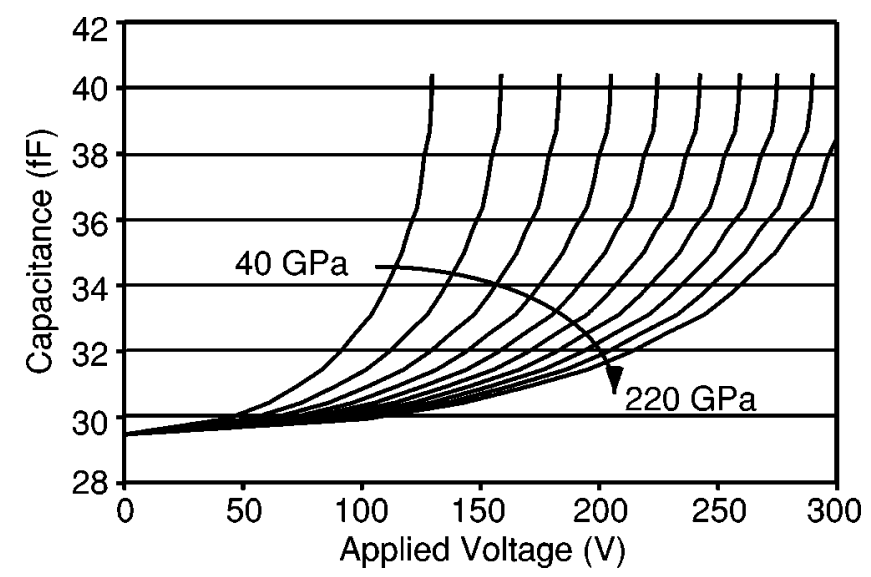

Fig. 4. Theoretical $C-V$ curves for $k_{\text {eff }}$ values representing Young's moduli of $40-220 \mathrm{GPa}$ in $20 \mathrm{GPa}$ increments assuming the bent-beam compliance dominates.

which include the contributions from the displacement of bentbeams, the bending of tines and the torsion of supporting ribs:

$$
\begin{aligned}
k_{\text {eff }} & =\frac{\left[\left(2 \cdot k_{b b}\right) \perp\left(N \cdot k_{\text {tine }}\right) \perp k_{\text {rib }}\right]}{2} \\
k_{b b} & =\frac{4 \cdot W_{b b} \cdot H \cdot E \cdot \sin ^{2} \phi}{L_{b b}} \\
k_{\text {tine }} & =\frac{2 \cdot E \cdot H \cdot W_{\text {tine }}^{3}}{3 \cdot L_{\text {tine }}^{3}} \\
k_{\text {rib }} & =\frac{2 \cdot E \cdot H \cdot W_{\text {rib }}^{3}}{L_{\text {rib }} \cdot\left(L_{\text {tine }}-0.5 \cdot L_{o v}\right)^{2}}
\end{aligned}
$$

where $k_{b b}$ is the compliance of one bent-beam, $k_{\text {tine }}$ is the compliance of one tine and $k_{\mathrm{rib}}$ is the compliance of one support rib. The rest of the symbols are as defined in Fig. 3. Equations (6) to (9) are verified to be within 17\% agreement with the FEA results obtained using ANSYS [21]. In the preferred implementation, $k_{b b} \ll N \cdot k_{\text {tine }}$ and $k_{b b} \ll k_{\text {rib }}$; the compliance of bent-beam will dominate.

Fig. 4 shows calculated $C-V$ curves obtained by this method showing the effect of change in Young's modulus assuming that the compliance of the tines and rib is negligible $\left(k_{b b} \ll N \cdot k_{\text {tine }}\right.$ and $k_{b b} \ll k_{\text {rib }}$ ). In effect, each of the curves shown in the figure has a different spring constant; for a lower Young's modulus, the spring is softer, causing the response to veer up at a smaller applied voltage. For these simulations, the suspension had the 


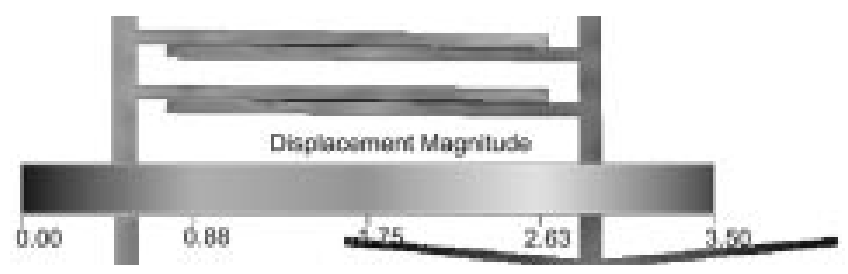

Fig. 5. FEA displacement plot of two tine pairs under applied voltage.

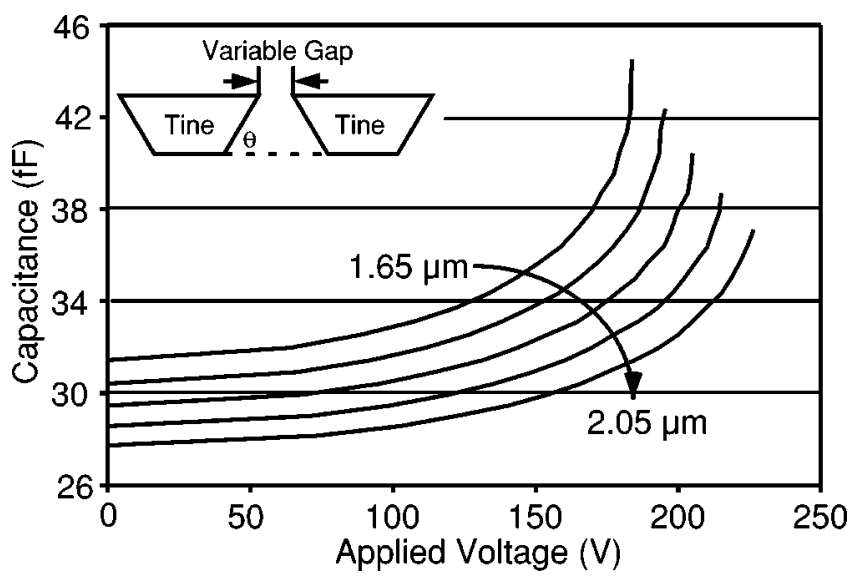

Fig. 6. Calculated curves showing the impact of variation of the initial gap on the $C-V$ response.

following dimensions: $L=198 \mu \mathrm{m}, W=5 \mu \mathrm{m}, \theta=0.1 \mathrm{rad}$, $4.4 \mu \mathrm{m}$ thickness. Ten pairs of tines were assumed with $167 \mu \mathrm{m}$ interdigitated overlap length. The sidewalls of the tines were assumed to have a reentrant profile that was $22^{\circ}$ off vertical (with a $68^{\circ}$ angle to the substrate) due to fabrication. The zero-bias gap between the upper edges of adjacent tines (where the tines were closest) was $1.85 \mu \mathrm{m}$. The tines were assumed to be $2.2 \mu \mathrm{m}$ above the substrate.

In order to generate curves shown in Fig. 4, the following procedure was followed. First the zero-bias capacitance of the tine structure was determined. This capacitance corresponds to the initial tine separation and was found by reading off the position in the numerically simulated capacitance table that was previously generated. The assumed separation between the opposing tines was then decremented infinitesimally. At each step, the capacitance was determined from the table and $V_{\text {bias }}$ was found by solving (5). The iterations were terminated when electrostatic pull-in occurred. An FEA simulation was also performed using commercially available CoventorWare software [22]. This confirmed the overall operation of the device. It also showed that even in situations that the tines are compliant, for small deflections the pairs of opposing tines remain roughly parallel even as they are deflected toward each other (see Fig. 5).

\section{Modeling of Nonidealities}

In order to better understand the impact of structural nonidealities upon the sensor behavior, several additional simulations were performed. In particular, variations in initial tine separation, tine sidewall angle and out-of-plane displacement of the tines were investigated. Such variations could conceivably be caused by poor process control. In all of these simulations, the nominal dimensions were as for Fig. 4 and the Young's modulus

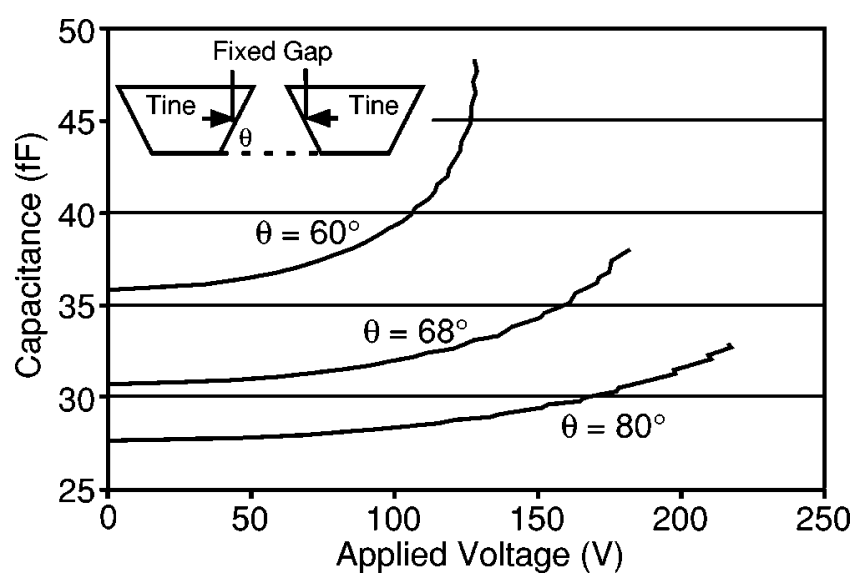

Fig. 7. Calculated $C-V$ curves showing the impact of varying the sidewall angles of tines.

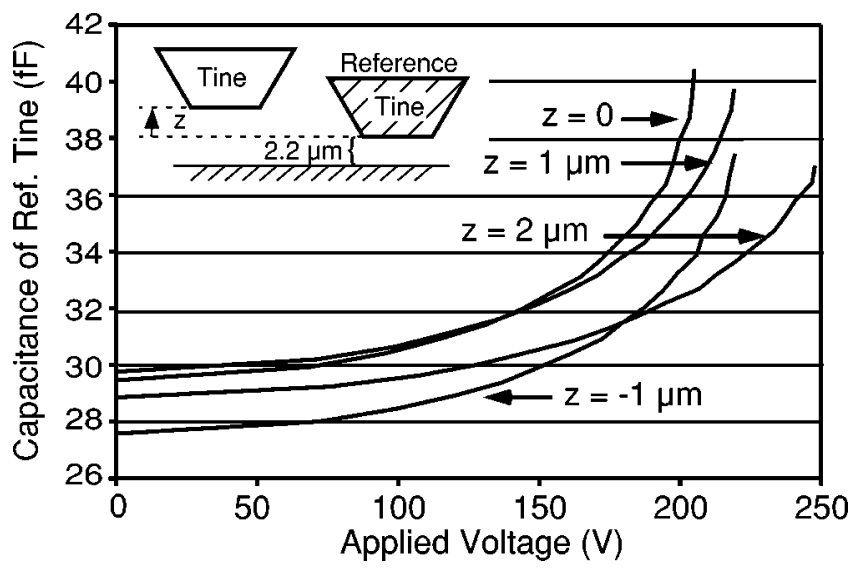

Fig. 8. Calculated $C-V$ curves showing the impact of out-of-plane deflection of tines.

was $100 \mathrm{GPa}$, unless specified otherwise. Fig. 6 shows variations in the $C-V$ curve caused by changing the initial gap between the upper edges of the tines from $1.65 \mu \mathrm{m}$ to $2.05 \mu \mathrm{m}$ in $0.1 \mu \mathrm{m}$ increments. It is clear that the zero-bias capacitance changes as expected, but the slopes of the $C-V$ curves remain roughly unchanged for bias values almost up to $150 \mathrm{~V}$. Fig. 7 shows the impact of changing the sidewall angles of the tines on the $C-V$ curves from $60^{\circ}$ to $80^{\circ}$ while keeping unchanged the mid-height spacing at the zero-bias value. Evidently, this can have a significant impact on both the intercepts and curvatures. This dimensional parameter should be tightly controlled. Fig. 8 shows how the total capacitance of a single tine varies as a neighboring tine is raised or lowered. Although the $C-V$ curve is shifted along the $y$-axis, the curvature is not significantly affected up to $150 \mathrm{~V}$. The out-of-plane deformation is minimal if the thickness-to-width aspect ratio is high. Typically, high-aspect ratio processes also provide exceptional control over sidewall angle, offering a suitable test implementation of such a device.

\section{FABRICATION}

Differential capacitive strain sensors were realized using three approaches. Set A used electroplated $\mathrm{Ni}$ as structural material with molds formed by standard UV lithography; set 


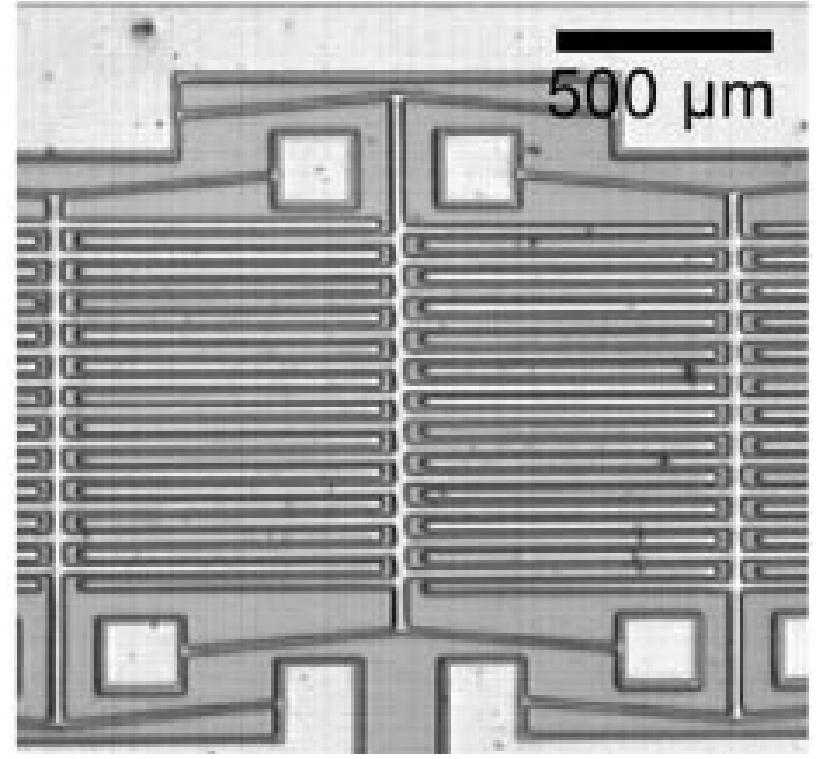

(a)

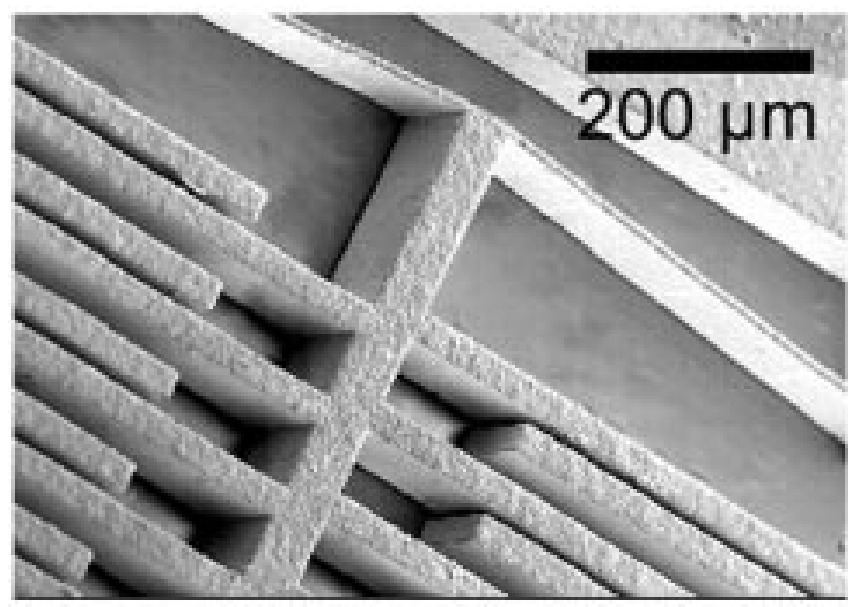

(b)

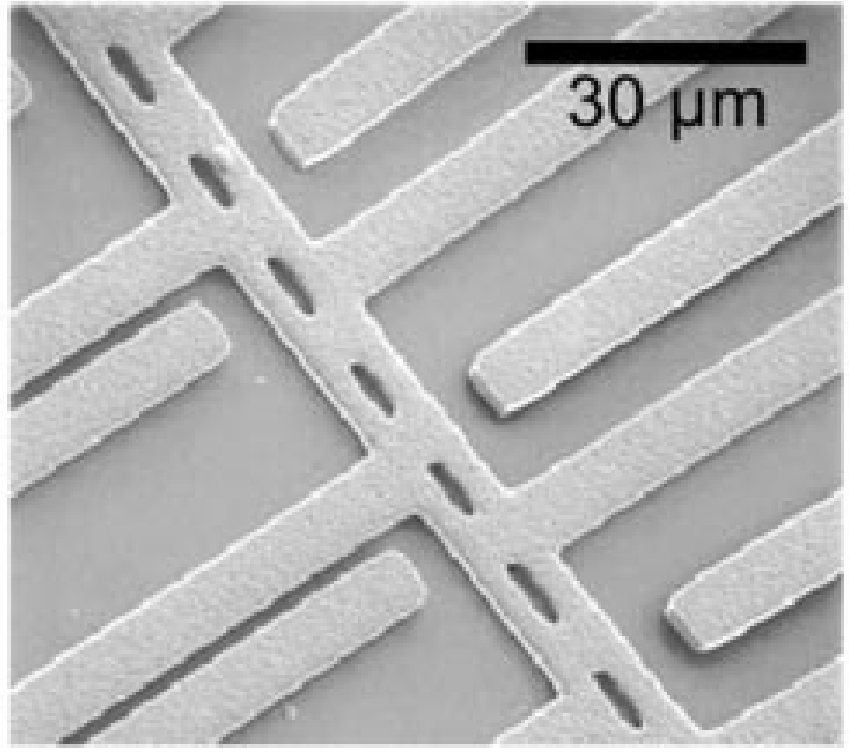

(c)

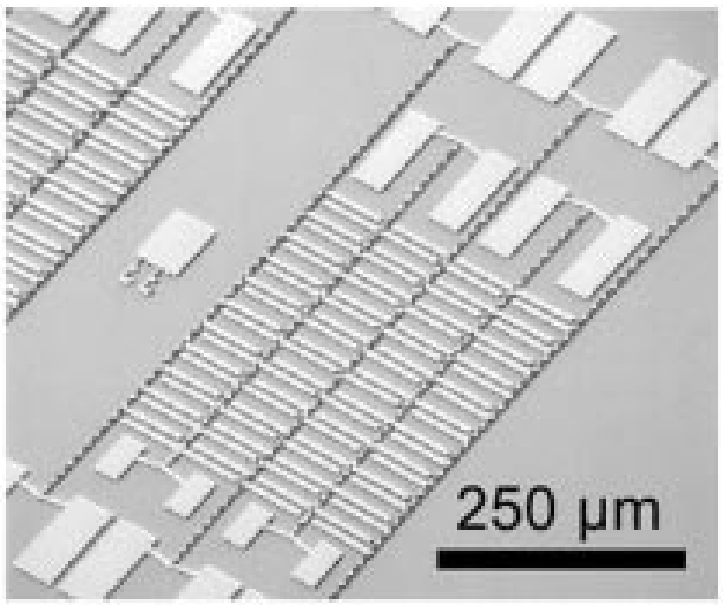

(d)

Fig. 9. Images of fabricated capacitive strain sensors: (a) set A, optical micrograph of a Ni structure, (b) SEM image of the set A variant denoted A0, (c) set B, LIGA Ni structure, and (d) set C poly Si structure.

$\mathrm{B}$, also using $\mathrm{Ni}$, was implemented with LIGA technology, with molds formed by collimated X-ray exposure; set $\mathrm{C}$ used LPCVD polysilicon in a surface micromachining process.

Set A was fabricated on silicon wafers insulated with $1 \mu \mathrm{m}$ thick thermal oxide and $0.5 \mu \mathrm{m}$ thick LPCVD nitride. A $2 \mu \mathrm{m}$ thick sputtered Ti sacrificial layer was patterned and covered with a $\mathrm{Cr} / \mathrm{Ni}$ seed layer. The devices were electroplated into a photoresist mold from a nickel sulphamate solution. At $54^{\circ} \mathrm{C}$ temperature, using $5-10 \mathrm{~mA} / \mathrm{cm}^{2}$ current density, a thickness of $4.4 \mu \mathrm{m}$ was achieved in $9.5 \mathrm{~min}$. The electroplating was performed using a nickel anode in a $1500 \mathrm{~mL}$ Pyrex beaker with $1000 \mathrm{~mL}$ of plating solution agitated with a motor. The sidewalls of the plated structures were $68^{\circ}$ to the substrate due to resist reflow during the hard bake. (This can be determined from the thickness of the mold and the difference between the line widths at the bottom and the top of the feature.) The photoresist mold was subsequently stripped and the sacrificial material etched away. Following this, the sample was coated with a self-assembled monolayer using octyltriethoxysilane (ODS, $\left.\mathrm{CH}_{3}\left(\mathrm{CH}_{2}\right)_{7} \mathrm{Si}\left(\mathrm{OC}_{2} \mathrm{H}_{5}\right)_{3}\right)$ [17]. Octyltriethoxysilane is preferred over other alternatives, such as octadecyltrichlorosilane (OTS) and perfluorodecyltrichlorosilane (FTDS), because ODS is less sensitive to moisture contamination and yields an advancing contact angle of $93^{\circ}$ for water on an oxidized $\mathrm{Si}$ wafer. It was found that the ODS solution remained effective in excess of $24 \mathrm{~h}$ after the preparation of the chemical under normal laboratory conditions. An optical image of a fabricated structure is shown in Fig. 9(a).

In a variant of set $\mathrm{A}$ denoted set $\mathrm{A} 0$, the current density and temperature used for the electroplating step were modified, producing tensile $\mathrm{Ni}$ which had 192-264 $\mu$ strain at room temperature. A structure from this set is shown in Fig. 9(b).

Set B was fabricated on (\#7740) glass substrates using LIGA technology [23]. These devices were plated on a $2-\mu \mathrm{m}$-thick 
sacrificial layer using a $\mathrm{Ni}$ sulphamate solution which had $\mathrm{Ni}$ concentration of $82 \mathrm{~g} / \mathrm{L}$. At $56^{\circ} \mathrm{C}$ temperature and $32 \mathrm{~mA} / \mathrm{cm}^{2}$ current density, a thickness of $55 \mu \mathrm{m}$ was achieved in $95 \mathrm{~min}$ [see Fig. 9(c)]. The electroplating was performed with a nickel anode in a $400 \mathrm{~mL}$ tank with a pump and a filter. The increased thickness provides large sidewall capacitance, which improves sensitivity and reduces measurement uncertainty. Thick structures also eliminate out-of-plane deformation and resist buckling even when highly compressive forces are encountered. The LIGA devices also benefit from precise dimensional control and from vertical sidewalls.

Set $\mathrm{C}$, the polysilicon devices, were fabricated on a Si substrate with a $2-\mu \mathrm{m}$ oxide isolation layer capped by a $1-\mathrm{k} \AA$-thick LPCVD nitride layer. The sacrificial layer was $2.5 \mu \mathrm{m}$ thick PECVD oxide, while the structural layer was $2.5 \mu \mathrm{m}$ LPCVD polysilicon deposited at $600^{\circ} \mathrm{C}$ in two layers, between which a phosphorus implant of $1 \times 10^{16} \mathrm{~cm}^{-2}$ was performed. The polysilicon was annealed at $1000^{\circ} \mathrm{C}$ for $30 \mathrm{~min}$ and patterned by an $\mathrm{SF}_{6}$ and $\mathrm{O}_{2}$ reactive ion etch (RIE). The sacrificial layer was etched in buffered HF acid. A device is shown in Fig. 9(d).

\section{EXPERIMENTAL RESULTS}

This section describes measurements of fabricated samples. Residual strain measurements and the extraction of thermal expansion coefficients are described first followed by $C-V$ measurements of Young's modulus. The performance of the capacitive strain sensors was verified in both tensile and compressive material.

\section{A. Thermal Expansion Coefficient and Residual Strain Measurements}

Passive bent beam strain sensors [10] were located adjacent to the capacitive devices in the layout. Vernier readings from these devices were used to determine the local residual strain and using this information the expected values of differential capacitance were calculated by the analytical approach described in the modeling section. In addition, samples were heated and strains were measured as a function of temperature.

The $\alpha$ for Ni deposited in set A was first measured by passive bent-beam strain sensors, with $L=198 \mu \mathrm{m}, W=6 \mu \mathrm{m}$ and $\theta=0.1 \mathrm{rad}$. Strain was measured as a function of temperature by visually monitoring their deformations and compensating for $\alpha$ of $\mathrm{Si}$, which changes from $2.5 \mathrm{ppm} / \mathrm{K}$ at $23^{\circ} \mathrm{C}$ to $4 \mathrm{ppm} / \mathrm{K}$ at $500^{\circ} \mathrm{C}[24]$

$$
\alpha_{\text {Metal }}(T)=\alpha_{\mathrm{Si}}(T)-\frac{d(e(T))}{d T}
$$

where $e(T)$ is the strain observed by the strain sensor. The residual strain changed from $1.1 \times 10^{-10}$ at $23^{\circ} \mathrm{C}$ to -880 microstrain at $100^{\circ} \mathrm{C}$. The $\alpha$ for $\mathrm{Ni}$ used in set $\mathrm{A}$ increased from $\approx 13.5 \mathrm{ppm} / \mathrm{K}$ at $50^{\circ} \mathrm{C}$ to $\approx 16.5 \mathrm{ppm} / \mathrm{K}$ at $150^{\circ} \mathrm{C}$ (see Fig. 10). This compares well with previously published results. One report indicates that $\alpha$ for $\mathrm{Ni}$ increases from $10.2 \mathrm{ppm} / \mathrm{K}$ at $20^{\circ} \mathrm{C}$ to $16.3 \mathrm{ppm} / \mathrm{K}$ at $300^{\circ} \mathrm{C}$ and holds the latter value at $400^{\circ} \mathrm{C}$ as well [25]. Another report indicates that $\alpha$ for Ni electroplated under particular conditions may increase from $8.5 \mathrm{ppm} / \mathrm{K}$ averaged over the temperature range from 25 to

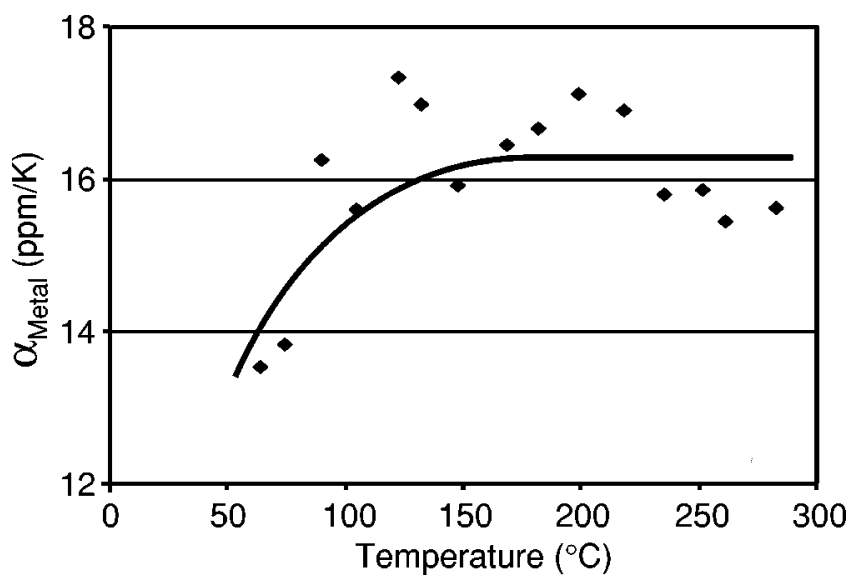

Fig. 10. The thermal expansion coefficient of the structural metal as measured by passive bent-beam strain sensors.

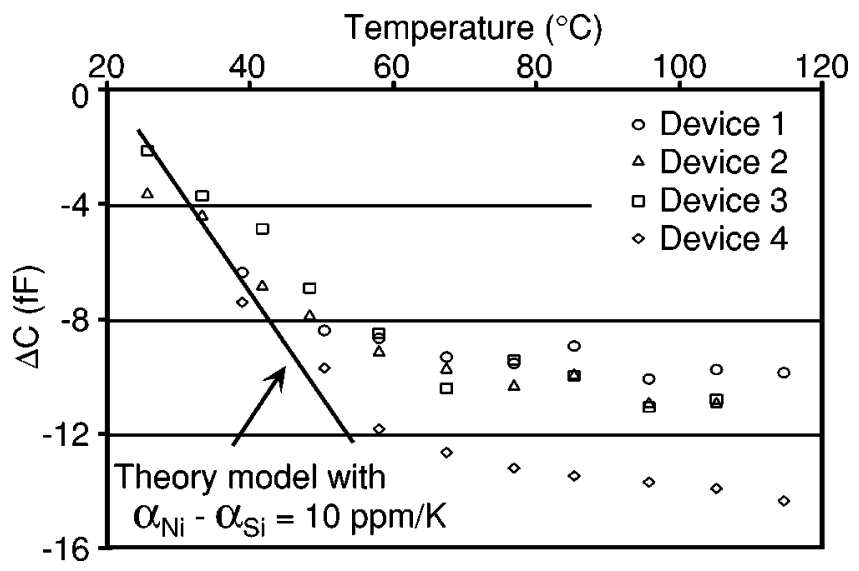

Fig. 11. The thermal expansion coefficient of the structural metal as measured by four adjacent differential capacitive strain sensors. The support ribs buckled near $60^{\circ} \mathrm{C}$

$50^{\circ} \mathrm{C}$ to $15.1 \mathrm{ppm} / \mathrm{K}$ averaged over the temperature range of $25-367^{\circ} \mathrm{C}$ [26].

The capacitive strain sensors were then used to monitor the $\mathrm{Ni}$ residual strain in set A as a function of temperature. Measurements from four adjacent devices showed a linear increase in differential capacitance from $20^{\circ} \mathrm{C}$ to $60^{\circ} \mathrm{C}$ (see Fig. 11). Measurements were taken with $\pm 0.5 \mathrm{fF}$ precision using a device with 10 tine pairs with $168 \mu \mathrm{m}$ overlap length and $5 \mu \mathrm{m}$ nominal gap, suspensions with $L=198 \mu \mathrm{m}, W=6 \mu \mathrm{m}$ and $\theta=0.2 \mathrm{rad}$. and ribs with $L=438 \mu \mathrm{m}$ and $W=10 \mu \mathrm{m}$. The device response to increasing temperature was theoretically estimated using FastCap ${ }^{\mathrm{TM}}$, assuming that the average $\alpha$ for $\mathrm{Ni}$ exceeds that for Si by $10 \mathrm{ppm} / \mathrm{K}$. This result is superimposed on the measured data in Fig. 11. Based on the passive strain sensor measurements (see Fig. 10) and previously published results, the expansion mismatch between nickel and silicon over $20-60^{\circ} \mathrm{C}$ was $6-11 \mathrm{ppm} / \mathrm{K}$, consistent with the differential capacitance measurements. At temperatures $>60^{\circ} \mathrm{C}$, however, the 4.4- $\mu \mathrm{m}$ thick devices were affected by out-of-plane buckling of the support ribs. This suggests dimensional constraints for device designs.

In the variant of set $\mathrm{A}$ denoted $\mathrm{A} 0$, a device with dimensions of $L=100 \mu \mathrm{m}, W=4 \mu \mathrm{m}$ and $\theta=0.1 \mathrm{rad}$. with 18 tine pairs at $1.3 \mu \mathrm{m}$ separation and $91 \mu \mathrm{m}$ overlap, was expected to 


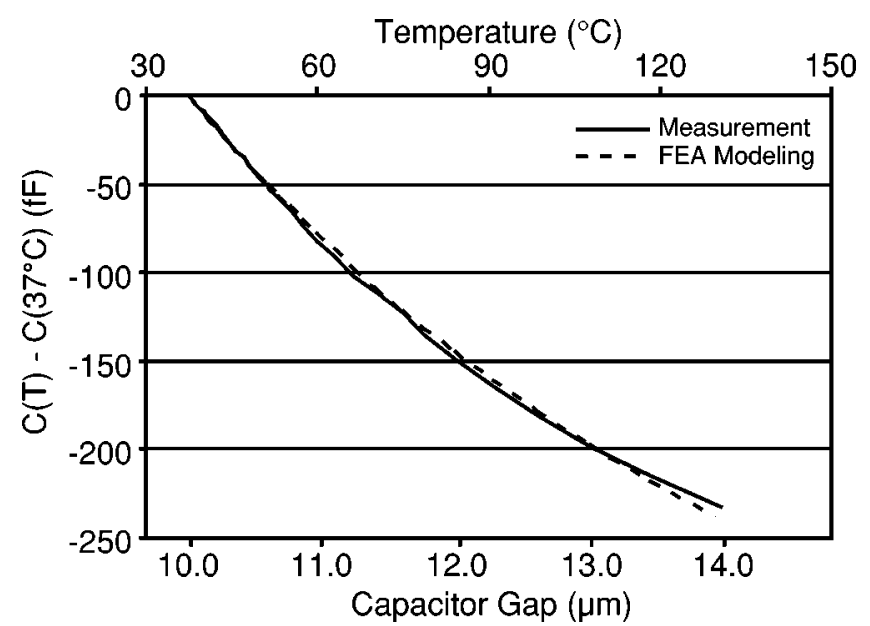

Fig. 12. Capacitance change referenced to the neutral position for a LIGA device.

produce a $\Delta C=5.7 \mathrm{fF}$. In comparison, the measured value was $4.8 \mathrm{fF}$.

The $\Delta C$ measurements of a set $\mathrm{B}$ device indicated that the residual strain was +68.5 microstrain at $23^{\circ} \mathrm{C}$ and -236 microstrain at $85^{\circ} \mathrm{C}$. These values were determined by fitting the measured $\Delta C$ to calculated values using the procedure outlined in the Section II. This device had 24 tines in each of four banks, with $900 \mu$ m overlap length, $1040 \mu \mathrm{m}$ total length, $29 \mu \mathrm{m}$ width and $10 \mu \mathrm{m}$ nominal gap; suspensions with $L=1000 \mu \mathrm{m}$, $W=10 \mu \mathrm{m}$ width and $\theta=0.1 \mathrm{rad}$; and ribs with $L=$ $2550 \mu \mathrm{m}$ and $W=45 \mu \mathrm{m}$. The $\alpha$ for Ni was calculated for set B devices by using (10) and the capacitively measured values of strain. After accounting for the $\alpha$ for \#7740 glass which is $3.25 \mathrm{ppm} / \mathrm{K}$ [24], these measurements indicate that $\alpha$ for Ni that was plated for set $\mathrm{B}$ devices was $8.2 \mathrm{ppm} / \mathrm{K}$ when averaged over $23-85^{\circ} \mathrm{C}$, which falls within the range previously reported [26]. Further confirmation of the expansion coefficient was obtained by using the change in $C_{A C}$ alone as a function of temperature. The calculated and measured capacitances were referenced to the $C_{A C}$ at $37^{\circ} \mathrm{C}$, which was the interpolated zero-stress temperature (Fig. 12). The close fit indicates that $\alpha$ for $\mathrm{Ni}$ was $7.9 \mathrm{ppm} / \mathrm{K}$. At $130^{\circ} \mathrm{C}$ the calculated increase in the gap between the tines (with respect to the zero-stress position) was $3.95 \mu \mathrm{m}$, corresponding to a residual strain of -420 microstrain. This matched with the calibrated visual measurement of $\approx 3.7 \mu \mathrm{m}$.

In the set $\mathrm{C}$ devices, the residual stress measured by the passive strain sensors was compressive, at 250-260 $\mu$ strain. For a device with suspension length of $100 \mu \mathrm{m}$, width of $4 \mu \mathrm{m}$, thickness of $2.5 \mu \mathrm{m}$ and a bending angle of $0.2 \mathrm{rad}$ with 22 tine pairs at a separation $3 \mu \mathrm{m}$ and overlap of $112 \mu \mathrm{m}$, this suggests a reading of $\Delta C=3.7 \mathrm{fF}$. In comparison, the measured value was $5.0 \mathrm{fF}$.

\section{B. C-V Measurements, Young's Modulus, and Residual Stress}

Although the Young's modulus of bulk nickel is $208 \mathrm{GPa}$, electroplated nickel demonstrates significant variability depending on deposition conditions such as current density and can have a substantially lower modulus [27]. This underscores the need for in situ material property measurements. For Ni electroplated under particular conditions, a value of $150 \mathrm{GPa}$

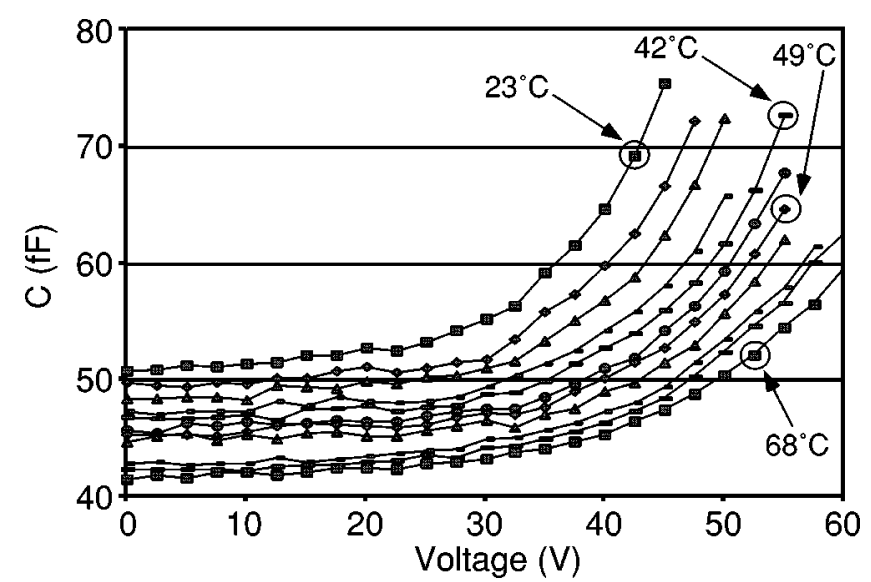

Fig. 13. Measured $C-V$ as a function of temperature for surface micromachined $\mathrm{Ni}$ structure. The buckling temperature for this device was $>70^{\circ} \mathrm{C}$.

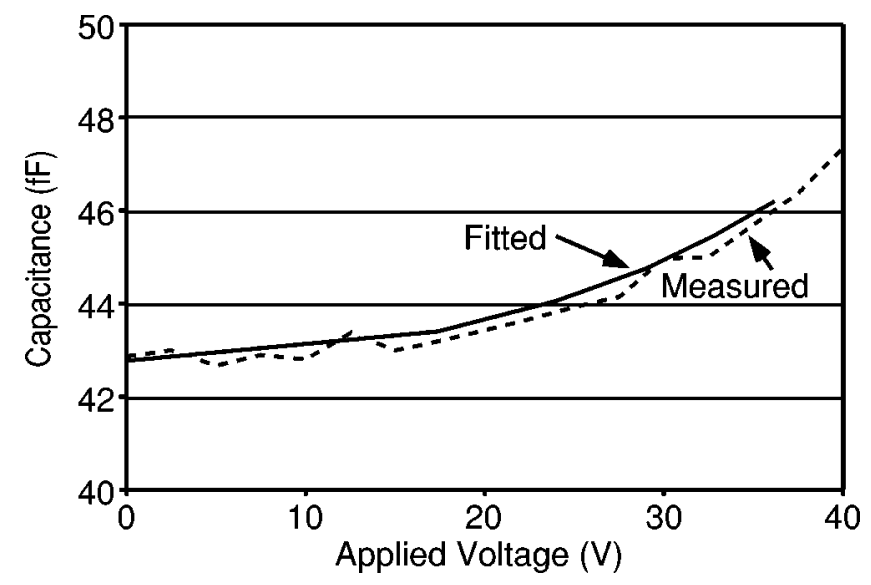

Fig. 14. Comparison of a measured $C-V$ curve from Fig. 13 to a fitted theoretical curve. $T=60^{\circ} \mathrm{C}$.

was reported in [28] using a resonant beam technique. Another study based on precision tensile machine tests reported $158 \mathrm{GPa}$ and $181 \mathrm{GPa}$ for two separate runs done at the same foundry [5], [29]. Another study concluded that the modulus decreased from $156 \mathrm{GPa}$ to $131 \mathrm{GPa}$ when the electroplating current density was increased from 20 to $70 \mathrm{~mA} / \mathrm{cm}^{2}$ when using a nickel sulfate-based bath [27]. Yet another study reported a Young's modulus of $231 \mathrm{GPa}$ using a technique similar to the tensile machine method [31].

Fig. 13 shows CV curves that were measured at various temperatures for set A devices with dimensions as noted previously, except $\theta=0.1 \mathrm{rad}$. Numerically simulated curves were fitted to measurements using the zero bias capacitance and the Young's modulus as fitting parameters. A comparison of a measured and fitted curve pair is shown in Fig. 14. The best fit of $k_{\text {eff }}$ corresponded to a Young's modulus of $135 \pm 15 \mathrm{GPa}$ at $23^{\circ} \mathrm{C}$ for the electroplated metal.

Measurements for the set B device are plotted in Fig. 15 as fractional changes in measured capacitance, i.e., $[C(V) / C(V=0)]-1$, against $V^{2}$. In this representation, the $y$-axis is proportional to the fractional change in the gap between the tines, while the $x$-axis is proportional to the electrostatic force. At $23^{\circ} \mathrm{C}$ the best fit corresponds to a 


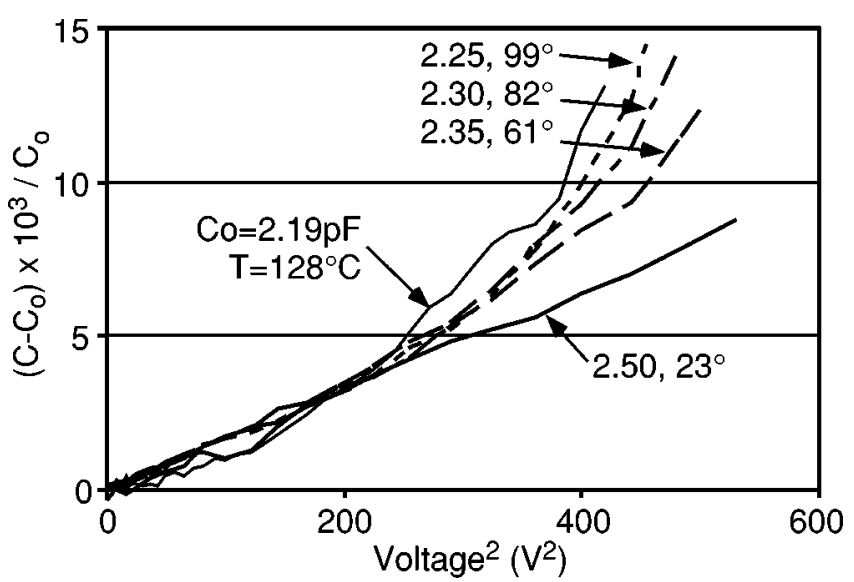

Fig. 15. Measured $C_{A C}$ for set B sensors at various temperatures. $C_{0}$ is the measured $C_{A C}$ at $V=0$.

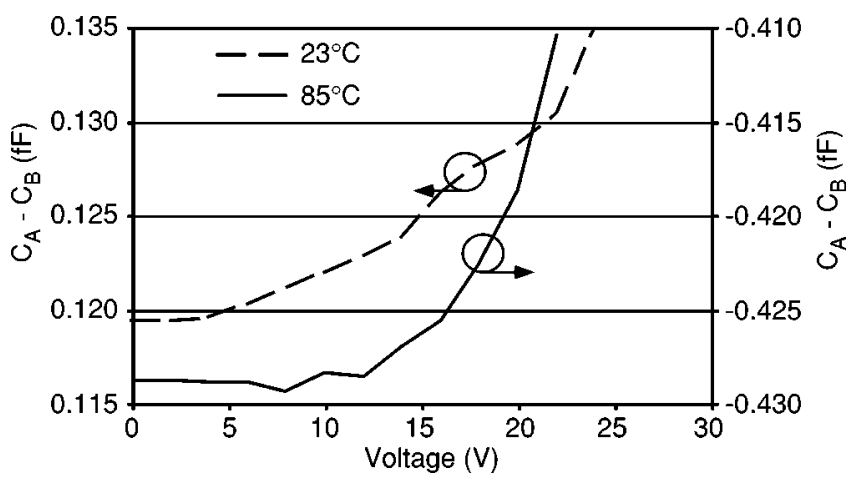

Fig. 16. Measured $\Delta C$ for set B strain sensors at two temperatures.

Young's modulus of $115 \pm 10 \mathrm{GPa}$. Some of the uncertainty is attributable to the calculation of fringing fields and the impact of parasitics in measurements. These were eliminated from the strain measurements because $\Delta C$ was used instead of $C_{A C}$. Consequently, it may be possible to reduce the uncertainty by using $\Delta C$ measurements (Fig. 16). A set of curves such as this may be useful as a process control standard even if not used to extract the material properties.

Both the set A and set B devices showed that the Young's modulus of electroplated $\mathrm{Ni}$ decreased with increasing temperature. This is also evident from the trend in Fig. 15. The temperature coefficient of the Young's modulus, which is the same as that of $k_{\text {eff }}$, was estimated as $-1590 \mathrm{ppm} / \mathrm{K}$. There is significant uncertainty in this value because measurement and fitting errors are compounded. This parameter is also strongly dependent on fabrication conditions and values ranging from $-550 \mathrm{ppm} / \mathrm{K}$ [28] to $-952 \mathrm{ppm} / \mathrm{K}$ [24] have been reported previously.

To verify the measurements obtained using the differential capacitive strain sensor, a load-deflection test was done to measure the Young's modulus. Nickel specimens from set B with $W=1.55 \mathrm{~mm}, T=185 \mu \mathrm{m}$ and $L=45 \mathrm{~mm}$ were used in the test. The deflection specimen was mounted on a holder such that it was cantilevered with the boundary conditions of a fixed-free beam (see Fig. 17). Using a Chatillon TCD200 universal tensile tester (which can also provide compressive loads) which has a force resolution of $0.01 \mathrm{~N}$, a blade edge was lowered with precise motion control to exert a line force at a spe-

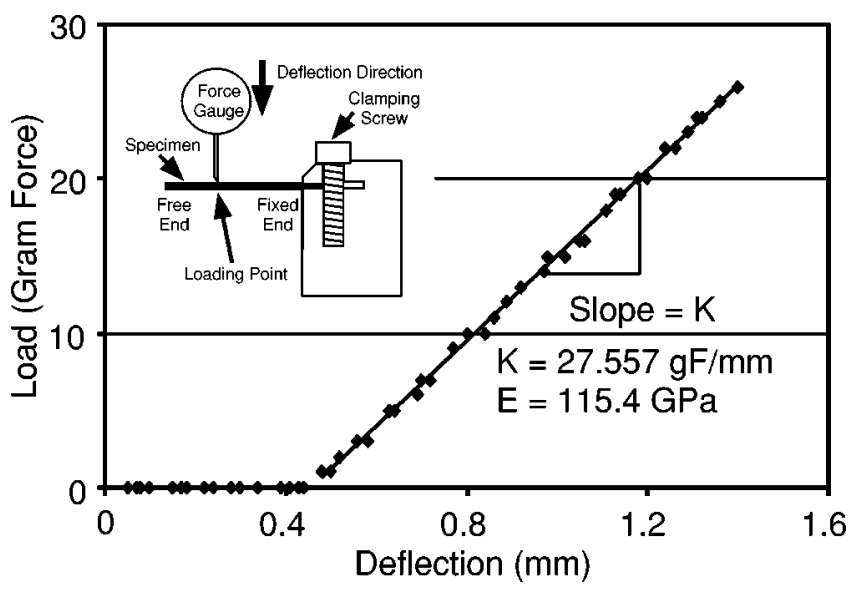

Fig. 17. A typical set of data obtained with the load-deflection measurement.

cific location. The force-displacement measurement yielded the effective spring constant of the cantilever and this spring constant was used to calculate the Young's modulus of the material. Using this method, 40 load-displacement curves were gathered with a loading force applied $7.6 \mathrm{~mm}$ from the clamped point. A typical load-deflection curve is shown in Fig. 17; for this particular measurement, the spring constant is 27.6 gram force per $\mathrm{mm}$ deflection. This spring constant translates into $E=115.4 \mathrm{GPa}$. The average of 40 such measurements yield a Young's modulus of $115.5 \mathrm{GPa}$ with a standard deviation of 4.3 GPa. These measurements agree well with the strain sensor reading of $115 \pm 10 \mathrm{GPa}$.

Using the measured values of strain and Young's modulus the thermal stress in the metal microstructures can be calculated in a piecewise linear manner. For the plating solution and conditions used in the set A devices, at $23^{\circ} \mathrm{C}$ the stress is essentially zero and at $100^{\circ} \mathrm{C}$ it is approximately $-105 \mathrm{MPa}$. The residual stress for the set $\mathrm{B}$ structure was $+7.88 \mathrm{MPa}$ at $23^{\circ} \mathrm{C}$ and $-27.1 \mathrm{MPa}$ at $85^{\circ} \mathrm{C}$ using $E=115 \mathrm{GPa}$. For set $\mathrm{C}$, in which the structural material was expansion matched to the substrate, the Young's modulus was not measured. However, using the widely used value of $160 \mathrm{GPa}$, the stress was $-40 \mathrm{MPa}$ to $-42 \mathrm{MPa}$ at room temperature.

Trace levels of contamination and variations in plating conditions can significantly affect the mechanical properties of electroplated materials. An X-ray energy-dispersive spectrum (XEDS) plot of the set A Ni plating sample indicated very minute contamination from $\mathrm{Cu}$ only.

\section{CONCLUSION}

In summary, the differential capacitive strain sensor is demonstrated to measure strain, Young's modulus and thermal expansion coefficient for both compressive and tensile materials. As a result, temperature dependency of these mechanical properties can be determined. For polysilicon, the stress is measured to be between $-40 \mathrm{MPa}$ and $-42 \mathrm{MPa}$. Also, it was found that the $\alpha$ for electroplated $\mathrm{Ni}$ was $8-16 \mathrm{ppm} / \mathrm{K}$ over $23-150^{\circ} \mathrm{C}$; the residual strain changed from neutral to -880 microstrain over $23-100^{\circ} \mathrm{C}$ in one case and +68.5 microstrain to -420 microstrain over $23-130^{\circ} \mathrm{C}$ in another case; and the Young's modulus ranged from 115-135 GPa at room tempera- 
ture. Theoretical calculations indicate that $C-V$ measurements can be affected by variations in device dimensions. However, when these are known a priori, the measurements of material properties provided by differential capacitive strain sensors are consistent with expectations. This device is suitable for monitoring fabrication and packaging process variables and may also be used to compensate other sensors over extended periods of deployment for drifts in material properties.

\section{ACKNOWLEDGMENT}

The authors gratefully acknowledge the late Prof. H. Guckel and Dr. B. Chaudhuri for helpful discussions. The authors also acknowledge Prof. P. Nealey and Dr. T. Kim for help with the self-assembled monolayer coating process, Prof. D. Stone for assistance in hardness testing and R. Noll for the XEDS results.

\section{REFERENCES}

[1] H. Guckel, T. Randazzo, and D. W. Burns, "A simple technique for the determination of mechanical strain in thin films with applications to polysilicon," J. Appl. Phys., vol. 57, no. 5, pp. 1671-1675, 1985.

[2] Y. B. Gianchandani, M. Shinn, and K. Najafi, "Impact of high-thermal budget anneals on polysilicon as a micromechanical material," J. Microelectromech. Syst., vol. 7, no. 1, pp. 102-105, Mar. 1998.

[3] Tencor ${ }^{\mathrm{TM}}$ FLX-2320 Manual, 1995.

[4] O. Tabata, K. Kawahata, S. Sugiyama, and I. Igarashi, "Mechanical property measurements of thin films using load-deflection of composite rectangular membrane," in Proc. IEEE Int. Workshop on Microelectromechanical Systems (MEMS '89), Jan. 1989, pp. 152-156.

[5] W. N. Sharpe Jr., D. A. LaVan, and R. L. Edwards, "Mechanical properties of LIGA-deposited nickel for MEMS," in Proc. Int. Conf. on SolidState Sensors and Actuators (Transducers 97), 1997, pp. 607-610.

[6] M. Mehregany, R. Howe, and S. Senturia, "Novel microstructures for the in situ measurement of the mechanical properties of thin films," $J$. Appl. Phys., vol. 62, no. 9, pp. 3579-3584, November 1987.

[7] L. B. Wilner, "Strain and strain relief in highly doped silicon," in Proc., Solid-State Sensor and Actuator Workshop (Hilton Head '92), June 1992, pp. 76-77.

[8] H. Guckel, D. Burns, C. Rutigliano, E. Lovell, and B. Choi, "Diagnostic microstructures for the measurement of intrinsic strain in thin films," $J$. Micromech. Microeng., vol. 2, pp. 86-95, 1992.

[9] B. P. van Drieenhuisen, J. F. L. Goosen, P. J. French, and R. F. Wolffenbuttel, "Comparison of techniques for measuring both compressive and tensile stress in thin films," Sens. Actuators, vol. A37-38, pp. 756-765, June-August 1993.

[10] Y. B. Gianchandani and K. Najafi, "Bent-beam strain sensors," J. Microelectromech. Syst., vol. 5, no. 1, pp. 52-58, Mar. 1996.

[11] L. Lin, A. Pisano, and R. Howe, "A micro strain gauge with mechanical amplifier," J. Microelectromech. Syst., vol. 6, no. 4, pp. 313-321, Dec. 1997.

[12] L. Que and Y. B. Gianchandani, "Mechanical properties and pattern collapse of chemically amplified photoresists," J. Vacuum Sci. Technol.-B, vol. 18 , no. 6, pp. 3450-3452, Nov. 2000.

[13] K. Najafi and K. Suzuki, "A novel technique and structure for the measurement of intrinsic stress and Young's modulus of thin films," in Proc. IEEE Int. Workshop on Microelectromechanical Systems (MEMS '89), Jan. 1989, pp. 96-97.

[14] P. M. Osterberg and S. D. Senturia, "M-TEST: A test chip for MEMS material property measurement using electrostatically actuated test structures," J. Microelectromech. Syst., vol. 6, no. 2, pp. 107-118, June 1997.

[15] B. E. Artz and L. W. Cathey, "A finite element method for determining structural displacements resulting from electrostatic forces," in Proc. Solid-State Sensor and Actuator Workshop, Hilton Head, SC, 1992, pp. 190-193.
[16] E. K. Chan, K. Garikipati, and R. W. Dutton, "Characterization of contact electromechanics through capacitance-voltage measurements and simulations," J. Microelectromech. Syst., vol. 8, pp. 208-217, June 1999.

[17] L. Que, M.-H. Li, L. Chu, and Y. B. Gianchandani, "A micromachined strain sensor with differential capacitive readout," in IEEE Int. Conf. on Micro Electro Mechanical Systems, Orlando, FL, Jan. 1999, pp. $552-557$.

[18] L. L. Chu, L. Que, and Y. B. Gianchandani, "Temperature coefficients of material properties using differential capacitive strain sensors," in Proc. Solid-State Sensor and Actuator Workshop, Hilton Head, SC, 2000, pp. 312-315.

[19] — , "Temperature coefficients of material properties for electrodeposited MEMS," in IEEE Int. Conf. on Micro Electro Mechanical Systems, Interlaken, Switzerland, Jan. 2001.

[20] K. Nabors, S. Kim, J. White, and S. Senturia, FastCap User's Guide: M.I.T., 1992.

[21] L. Que, "Micromachined Sensors and Actuators Based on Bent-Beam Suspensions," Ph.D., Univ. of Wisconsin, Madison, 2000.

[22] Coventor CoventorWare ${ }^{\mathrm{TM}}$ Version 2001.1 Manual, 2001.

[23] H. Guckel, "High-aspect ratio micromachining via deep X-ray lithography," Proc. IEEE, vol. 86, no. 8, pp. 1586-1593, Aug. 1998.

[24] W. H. Ko, J. T. Suminto, and G. J. Yeh, "Bonding techniques for micro sensors," in Micromachining \& Micropackaging of Transducers. New York: Elsevier, 1985.

[25] E. M. Wise and R. H. Schaeffer, "The properties of pure nickel-I," Metals and Alloys, pp. 424-428, Sept. 1942.

[26] J. W. Dini and H. R. Johnson, "Coefficient of thermal expansion of sulphamate nickel electrodeposits," J. Mater. Sci., vol. 10, no. 7, 1975.

[27] T. R. Christenson, T. E. Buchheit, D. T. Schmale, and R. J. Bourcier, "Mechanical and metallographic characterization of LIGA fabricated nickel and $80 \% \mathrm{Ni}-20 \%$ Fe permalloy," in Proc. Microelectromechanical Structures for Materials Research. Symposium, 1998, pp. 185-190.

[28] M. Putty, "A Micromachined Vibrating Ring Gyroscope," Ph.D. dissertation, Univ. of Michigan, Ann Arbor, 1995.

[29] W. N. Sharpe Jr. and A. McAleavey, "Tensile properties of LIGA nickel," in SPIE Conf. Materials and Device Characterization in Micromachining, vol. 3512, SPIE, 1998, pp. 130-137.

[30] L. S. Stephens, K. E. Kelly, E. I. Meletis, and S. Simhadri, "Mechanical property evaluation of electroplated high aspect ratio microstructures," in Proc. Microelectromechanical Structures for Materials Research. Symposium, 1998, pp. 173-178.

[31] S. Greek and F. Ericson, "Young's modulus, yield strength and fracture strength of microelements determined by tensile testing," in Proc. Microelectromechanical Structures for Materials Research. Symposium, 1998, pp. 151-156.

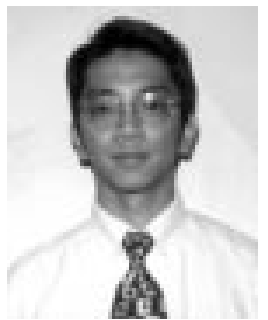

Larry L. Chu received the B.S. and M.S. degrees from the University of Wisconsin-Madison in 1998 and 2001, respectively, both in electrical and computer engineering. He is currently pursuing the Ph.D. degree in the same department and expects to complete the program in summer 2002.

From 1998 to present, he holds a research assistantship with the Microsystems Lab at the University of Wisconsin-Madison. Since 1998, he has worked on various aspects of micromachined structures for sensing and actuation and completed several projects from conceptualization to final device. He has been working on the design, optimization and application of electrothermal actuators and actuators in conjunction with compliant micro structures such as displacement amplifiers. He also worked on the characterization of materials using micro structures and various techniques for actuator fabrication. His current research interests include: the design and fabrication of microsystems that use actuators and the use of these microsystems in RF, optical, fluidic and microscopy applications. 


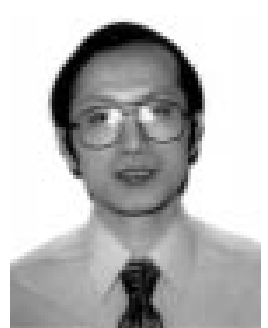

Long Que (S'98-M'01) received the B.S. degree in physics and the M.S.E.E. degree in optical communication from Peking University, Beijing, P. R. China, in 1990 and 1994, respectively. He received the M.S. and Ph.D. degree from University of Wisconsin-Madison in 1996 and 2000, respectively, all in electrical engineering.

From 1990 to 1993, he was a Research Engineer at the National Key Lab of Microfabrication on Optical Technology, Institute of Optics and Electronics, Chinese Academy of Sciences. From 1993 to 1994, he was a Research Assistant in the National Laboratory on Local Fiber-Optic Communication Networks \& Advanced Optical Communication Systems, Peking University. From January 1995 to June 2000, he was a Research Assistant at Center for Nanotechnology, ECE Microsystems Lab at University of Wisconsin at Madison. Since September, 2000, he joined as a R\&D Engineer, then Principal Engineer at OpticNet, Inc., Campbell, CA, where he has been developing optical components using MEMS techniques for WDM and DWDM optical communication networks.

Dr. Que received a national research award in the development of submicron and deep submicron IC technology from Chinese Academy of Sciences in 1997. He received the Vilas development fellowship from University of Wisconsin-Madison in 2000 for his dissertation research work. He has published more than a dozen papers in journals and conferences in optics, nanotechnology and MEMS areas. He has six patents pending. He is a Member of SPIE.

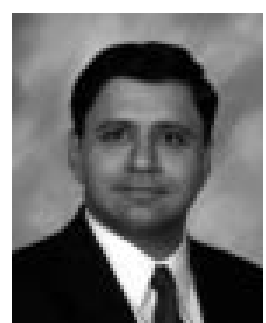

Yogesh B. Gianchandani (S'83-M'95) received the B.S., M.S., and Ph.D. degrees in electrical engineering from University of California, Irvine, University of California, Los Angeles, and University of Michigan, Ann Arbor, in 1984, 1986, and 1994, respectively.

From 1985 to 1989 , he held industry positions with Xerox Corporation and Microchip Technology, Inc., working in the area of integrated circuit design. From 1994 to 2001, he held various positions first at the University of Michigan and then at the University of Wisconsin-Madison. In 2002, he returned to the University of Michigan, where he is currently an Associate Professor in the Electrical Engineering and Computer Science Department. His research interests include all aspects of design, fabrication and packaging of micromachined sensors and actuators and their interface circuits.

Prof. Gianchandani received the National Science Foundation Career Award in 2000. He serves on the editorial boards of the IOP Journal of Micromechanics, Journal of Semiconductor Science and Technology, and Microengineering and Sensors and Actuators. He also serves on the steering and technical program committees for the IEEE International Conference on Micro Electro Mechanical Systems (MEMS) and served as the General Co-Chair for this meeting in January 2002. 